\title{
Painful and stressful procedures and analgesia in newborns from the viewpoint of professionals
}

\author{
Procedimentos dolorosos, estressantes e analgesia em neonatos na visão dos profissionais
}

Procedimientos dolorosos, estresantes y analgesia en neonatos bajo la perspectiva de los profesionales

\section{Etiene Leticia Leone de Moraes' ORCID: 0000-0003-0286-7874 \\ Márcia Helena de Souza Freire' ORCID: 0000-0003-3941-3673}

'Universidade Federal do Paraná. Curitiba, Paraná, Brazil.

How to cite this article:

Moraes ELL, Freire MHS. Painful and stressful procedures and analgesia in newborns from the viewpoint of professionals. Rev Bras Enferm. 2019;72(Suppl 3):170-7. doi: http://dx.doi.org/10.1590/0034-7167-2018-0326

\section{Corresponding Author:}

Etiene Leticia Leone de Moraes E-mail: etieneleticia@hotmail.com

\section{ABSTRACT}

Objective: To identify the procedures considered painful and stressful by health professionals from a neonatal intensive care unit and check the measures of analgesia. Method: Descriptive exploratory quantitative study with 65 health professionals, from November 2016 to February 2017. Results: The procedures considered painful were removal of adhesives, vein, arterial and lumbar puncture, phlebotomy, and thoracic drainage. Oral suctioning, intravenous catheter removal and tracheal extubation were considered stressful. Fentanyl was the most cited pharmacological measure, and restraint and nonnutritive suction were the most used nonpharmacological measures. Conclusion: Professionals were able to classify the painful and stressful procedures; however, low use of measures for analgesia was evidenced.

Descriptors: Acute Pain; Pain Management; Critical Pathways; Neonatal Intensive Care Unit; Health Team.

\section{RESUMO}

Objetivo: Identificar os procedimentos considerados dolorosos e estressantes pelos profissionais de saúde de uma unidade de terapia intensiva neonatal e verificar as medidas de analgesia. Método: Estudo descritivo, exploratório, com abordagem quantitativa, com amostra de 65 profissionais de saúde, no período de novembro de 2016 a fevereiro de 2017. Resultados: Os procedimentos considerados dolorosos foram a retirada de adesivos, a punção venosa, arterial e lombar, a flebotomia e a drenagem torácica. A aspiração oral, a retirada de cateter intravenoso e a extubação traqueal foram consideradas estressantes. O fentanil foi a medida farmacológica mais citada e a contenção e sucção não nutritiva as medidas não farmacológicas mais utilizadas. Conclusão: Os profissionais souberam classificar os procedimentos em dolorosos e estressantes, entretanto, foi evidenciada a baixa utilização de medidas para analgesia.

Descritores: Dor Aguda; Manejo da Dor; Procedimentos Clínicos; Unidade de Terapia Intensiva Neonatal; Pessoal de Saúde.

\section{RESUMEN}

Objetivo: Identificar los procedimientos considerados dolorosos y estresantes por los profesionales de salud en una unidad de cuidados intensivos neonatal y verificar las medidas de analgesia utilizadas. Método: Estudio descriptivo, exploratorio, de abordaje cuantitativo, con una muestra de 65 profesionales de salud, realizado en el período de noviembre de 2016 a febrero de 2017. Resultados: Los procedimientos considerados dolorosos fueron la retirada de adhesivos, la punción venosa, arterial y lumbar, la flebotomía y el drenaje torácico. Ya los considerados estresantes fueron la aspiración oral, la retirada del catéter intravenoso y la extubación traqueal. La medida farmacológica más citada fue el fentanilo; y las medidas no farmacológicas más utilizadas fueron la contención y la succión no nutritiva. Conclusión: Los profesionales pudieron clasificar los procedimientos en dolorosos y estresantes, sin embargo, se evidenció la baja utilización de medidas para analgesia.

Descriptores: Dolor Agudo; Manejo del Dolor; Vías Clínicas; Unidade de Cuidado Intensivo Neonatal; Personal de Salud. 


\section{INTRODUCTION}

Hospitalization in neonatal intensive care unit (NICU) causes newborns to be exposed to several painful procedures, many of them being necessary for diagnostic and therapeutic purposes ${ }^{(1-2)}$. However, many painful procedures are performed without any kind of analgesia administered by the multidisciplinary team and may contribute to consequences for their neurobehavioral and cognitive development in the medium and long term ${ }^{(3)}$.

Studies show gaps between the health professionals' knowledge and practice for the management of pain in newborns and, in general, the use of analgesic measures is poor or insufficient ${ }^{(4)}$.

Several ongoing studies aim to draw attention to the problem and to the need for change in the professional practice, through the adoption of protocols of analgesia and reduction in stress and suffering. Thus, an epidemiological study conducted in Paris in 13 neonatal intensive care units with 430 newborns (NB), whose gestational age ranged between 24 and 42 weeks, hospitalized for 14 days highlighted the performance of 115 painful and stressful procedures per NB, with an average of 16 procedures a day ${ }^{(3)}$. An Indian study, with $101 \mathrm{NBs,}$, whose gestational age ranged between 24 and 40 weeks and birth weight varied between $650 \mathrm{~g}$ and 3,635 $\mathrm{g}$, identified the performance of about 8 painful procedures a day in the first 7 days, and almost 69 in the first 14 days ${ }^{(5)}$. This reality was also evidenced in Brazil, with NBs exposed to 6.6 invasive procedures a day, in a study conducted in a public medium-complexity teaching hospital, located in the city of São Paulo, Brazil, with a sample of 150 newborns admitted to the NICU from this hospital, and the frequency of pain and measures taken for their relief during the first 7 days of hospitalization were determined ${ }^{(6)}$.

This study is relevant considering the context of high incidence of procedures in NICUs and the gap and/or absence of technical/ scientific knowledge and of adherence to protocols for managing pain and stress in the scenario in question.

\section{OBJECTIVE}

To identify the procedures considered painful and stressful by the multidisciplinary team from a neonatal intensive care unit, in addition to checking the measures for analgesias adopted by this team during these procedures.

\section{METHOD}

\section{Ethical aspects}

This study is part of the thematic project "Hospitalização infantil \& tecnologias de cuidado: contribuindo com a prática de um hospital infantil", met the requirements of resolution No. $466 / 2012$ of the Brazilian National Health Council and was approved by the Ethics Committee of the Department of Health of Paraná (Sesa), on August 25, 2016.

\section{Study design, location and period}

A descriptive exploratory quantitative study, conducted from November 2016 to February 2017 in a NICU from a public children's hospital, consisting of 20 hospital beds, located in municipality of the metropolitan region of Curitiba, state of Paraná. This hospital is one of the units under state management, started operating in 2009 and had 60 beds at the time of the study, in addition to a reference center for pediatric specialties and an imaging center equipped for covering from the simplest examinations to computed tomography.

\section{Sample, inclusion criteria, and exclusion criteria}

Sixty-five health professionals (10 nurses, 10 physical therapists, 8 physicians and 37 nursing technicians) participated in the study, 98 of which worked in the service. The inclusion criteria were: to be a health professional at the NICU of the hospital for more than 6 months; to be part of a professional category that works in rostering system and provides direct care for NBs for 24 hours; to be a coordinator of healthcare teams: medical, nursing and physical therapy. Professionals who were not working due to holidays, work leave, or other reason for absence during the period of data collection were excluded from the study.

\section{Collection and organization of data}

Health professionals who were potential participants were contacted individually by the researcher in the neonatal unit. When informed about the objectives of this study and showing interest in participating, they signed an Informed Consent Form. Then, they received a self-administered questionnaire with a text containing guidelines on its filling, which should be returned filled out in the same day. Pilot application of the instrument developed was conducted with eight health professionals who work in a NICU of another public hospital of Curitiba to verify the clarity of the questions and whether they would have answers appropriate to the objectives proposed.

Each filling lasted, on average, 20 minutes. Nine rejections occurred due to denial or instrument not returned. Sixty-five professional were interviewed, among them: 10 nurses, 10 physical therapists, 8 physicians, and 37 nursing technicians.

This article shows some of the data collected concerning the characterization of the health professionals participating (gender, age, professional category, academic training, professional experience and professional qualifications related to neonatal pain) and of the knowledge and practice of each respondent on neonatal pain management.

Thus, in this study, health professionals verbalized their perception about the classification of the routine procedures in the NICU as painful, stressful and/or unpainful. For this classification, an existing definition was used ${ }^{(3)}$, since any painful procedure is stressful, but not every stressful procedure is painful.

Painful procedures were considered those that disrupt the integrity of the newborn's skin, causing injury or wound in the mucosa by inserting or removing materials into/from the airways, digestive tract or urinary tract, namely: nasal and tracheal suction, intubation (orogastric or bladder), venous catheterization, chest drainage, chest physical therapy, subcutaneous and intramuscular injection, central catheter insertion, tracheal intubation and extubation, arterial and vein puncture, heel puncture, removal 
of adhesive and treatment of wounds ${ }^{(3)}$.

In turn, stressful procedures are those that annoy and cause physical and psychological discomfort, which leads to newborns' imbalance regarding their environment. This category includes blood pressure measurement, oral suctioning, bath, nasal catheter insertion, stimulating massage, weighing, radiography (x-ray), electroencephalography and cranial ultrasound ${ }^{(3)}$.

\section{Analysis of results and statistics}

For organization and analysis of data, a database was created using Microsoft Excel (version 2013). Data were submitted to analysis of consistency by double typing, and correction of discrepancies. Descriptive analysis was carried according to the categories of professional training (nurse, physical therapist, physician and nursing technician) and results were shown in tables, with description of the means and standard deviations.

In the results with data whose distributions could be inferred (that is, when the basic assumptions of the hypothesis tests were met), Chi-square tests were used to compare the different

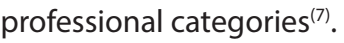

The statistical analyses were performed with the statistical package GraphPad Prism, considering a significance level of $5 \%$ $(a=0.05)$.

\section{RESULTS}

Among the health professionals participating, the female gender was prevalent (97\%). The age range was from 26 to 54 years for all categories, with the highest average evidenced in the category of nursing technicians (38.6 years) and also with the highest standard deviation (SD), being 7.4.
Regarding the graduate specialization, $70 \%$ of nurses and $100 \%$ of physical therapists and physicians were specialized. Some nursing technicians had higher education as nurses, and $5.4 \%$ of them $(n=2)$ reported being specialized. Regarding the graduate specialization, $20 \%(n=2)$ of nurses, $10 \%(n=2)$ of physical therapists and $12.5 \%(n=1)$ of physicians had the title of Master, and only one physician (12.5\%) had doctorate degree.

When asked about their experience in neonatology, $50 \%$ of nurses reported from 0 to 5 years of experience; and the others, from 6 to 10 years. Most (60\%) of the physical therapists mentioned experience from 0 to 5 years. In the category of physicians, $50 \%$ $(n=4)$ had from 6 to 10 years of experience. Among the nursing technicians, $43.2 \%(n=16)$ also reported from 6 to 10 years of experience in neonatology.

And when asked about having had professional training for the management of neonatal pain over the past five years, $40 \%$ of nurses, $20 \%$ of physical therapists, $38 \%$ of physicians, and $13.5 \%$ of nursing technicians declared participation in courses or scientific events.

However, concerning the participation in training on neonatal pain over the past 12 months, $10 \%$ of nurses, $12.5 \%$ of physicians and $13.5 \%$ of nursing technicians answered affirmatively.

More specifically regarding the perception of pain and stress related to routine procedures in newborns, all health professionals considered the removal of adhesives, vein puncture, arterial puncture, lumbar puncture, insertion of phlebotomy, and chest drainage painful procedures (Tables 1 and 2).

In Table 3, the frequency of endotracheal tube and airway suctioning with analgesia proved to be significantly different between the professional categories; nurses and physical therapists with frequencies greater( $60 \%$ and $70 \%$, respectively) than those of physicians and nursing technicians ( $25 \%$ and $16.2 \%$, respectively).

Table 1 - Classification of procedures performed in the neonatal intensive care unit as painful, stressful and unpainful, according to the professional category of nursing (nurses and nursing technicians), Campo Largo, Paraná, Brazil, 2017

\begin{tabular}{|c|c|c|c|c|c|c|c|c|c|c|c|c|}
\hline \multirow[b]{2}{*}{ Procedure } & \multicolumn{6}{|c|}{ Nurse $(n=10)$} & \multicolumn{6}{|c|}{ Nursing technicians $(n=37)$} \\
\hline & $\mathbf{n}$ & P $\%$ & $\mathbf{n}$ & $\%$ & $\mathbf{n}$ & $\%$ & $\mathbf{n}$ & $\%$ & $\mathbf{n}$ & $\%$ & $\mathbf{n}$ & U \% \\
\hline Fundoscopy & 8 & 80 & 2 & 20 & 0 & 0 & 22 & 59.4 & 14 & 37.8 & 1 & 2.7 \\
\hline Lumbar puncture & 10 & 100 & 0 & 0 & 0 & 0 & 37 & 100 & 0 & 0 & 0 & 0 \\
\hline Postoperative care & 10 & 100 & 0 & 0 & 0 & 0 & 36 & 97.3 & 0 & 0 & 0 & 0 \\
\hline Chest drainage & 10 & 100 & 0 & 0 & 0 & 0 & 37 & 100 & 0 & 0 & 0 & 0 \\
\hline Phlebotomy & 10 & 100 & 0 & 0 & 0 & 0 & 37 & 100 & 0 & 0 & 0 & 0 \\
\hline Intramuscular and subcutaneous injection & 10 & 100 & 0 & 0 & 0 & 0 & 36 & 97.3 & 0 & 0 & 1 & 2.7 \\
\hline Tracheal intubation & 10 & 100 & 0 & 0 & 0 & 0 & 31 & 83.8 & 5 & 13.5 & 1 & 2.7 \\
\hline Arterial Puncture & 10 & 100 & 0 & 0 & 0 & 0 & 37 & 100 & 0 & 0 & 0 & 0 \\
\hline Vein puncture & 10 & 100 & 0 & 0 & 0 & 0 & 37 & 100 & 0 & 0 & 0 & 0 \\
\hline Heel puncture & 10 & 100 & 0 & 0 & 0 & 0 & 36 & 97.3 & 0 & 0 & 0 & 0 \\
\hline PICC & 10 & 100 & 0 & 0 & 0 & 0 & 35 & 94.6 & 1 & 2.7 & 1 & 2.7 \\
\hline Tracheal suctioning & 7 & 70 & 3 & 30 & 0 & 0 & 14 & 37.8 & 22 & 59.4 & 1 & 2.7 \\
\hline Oral suctioning & 2 & 20 & 8 & 80 & 0 & 0 & 6 & 16.2 & 29 & 78.4 & 2 & 5.4 \\
\hline Umbilical catheter & 10 & 100 & 0 & 0 & 0 & 0 & 25 & 67.6 & 7 & 18.9 & 5 & 13.5 \\
\hline Gastric probing & 7 & 70 & 3 & 30 & 0 & 0 & 18 & 48.6 & 18 & 48.6 & 1 & 2.7 \\
\hline Extubation & 5 & 50 & 5 & 50 & 0 & 0 & 13 & 35.1 & 20 & 54.1 & 4 & 10.8 \\
\hline Removal of intravenous catheter & 7 & 70 & 3 & 30 & 0 & 0 & 18 & 48.6 & 17 & 45.9 & 2 & 5.4 \\
\hline Removal of adhesive & 10 & 100 & 0 & 0 & 0 & 0 & 37 & 100 & 0 & 0 & 0 & 0 \\
\hline Bath & 0 & 0 & 2 & 20 & 8 & 80 & 0 & 0 & 5 & 13.5 & 32 & 86.5 \\
\hline Anthropometric measurements & 0 & 0 & 4 & 40 & 6 & 60 & 3 & 8.1 & 20 & 54.1 & 16 & 43.2 \\
\hline Change of decubitus & 0 & 0 & 1 & 10 & 9 & 90 & 5 & 13.5 & 5 & 13.5 & 30 & 81.1 \\
\hline
\end{tabular}

Note: $P=$ painful; $S=$ stressful; $U$ = unpainful; $P I C C=$ peripherally inserted central catheter. 
Table 2 - Classification of procedures performed in the neonatal intensive care unit as painful, stressful and unpainful, according to the professional category of physicians and physical therapists, Campo Largo, Paraná, Brazil, 2017

\begin{tabular}{|c|c|c|c|c|c|c|c|c|c|c|c|c|}
\hline \multirow[b]{2}{*}{ Procedure } & \multicolumn{6}{|c|}{ Physical therapists $(n=10)$} & \multicolumn{6}{|c|}{ Physicians ( $(n=8)$} \\
\hline & $\mathbf{n}$ & $\begin{array}{l}P^{\prime} \\
\end{array}$ & $\mathbf{n}$ & $\%$ & $\mathbf{n}$ & U $\quad \%$ & $\mathbf{n}$ & P & $\mathbf{n}$ & $\%$ & $\mathbf{n}$ & $\begin{array}{l}\text { U } \\
\end{array}$ \\
\hline Fundoscopy & 6 & 60 & 4 & 40 & 0 & 0 & 4 & 50 & 3 & 37.5 & 1 & 12.5 \\
\hline Lumbar puncture & 10 & 100 & 0 & 0 & 0 & 0 & 8 & 100 & 0 & 0 & 0 & 0 \\
\hline Postoperative care & 10 & 100 & 0 & 0 & 0 & 0 & 8 & 100 & 0 & 0 & 0 & 0 \\
\hline Chest drainage & 10 & 100 & 0 & 0 & 0 & 0 & 8 & 100 & 0 & 0 & 0 & 0 \\
\hline Phlebotomy & 10 & 100 & 0 & 0 & 0 & 0 & 8 & 100 & 0 & 0 & 0 & 0 \\
\hline Intramuscular and subcutaneous injection & 10 & 100 & 0 & 0 & 0 & 0 & 8 & 100 & 0 & 0 & 0 & 0 \\
\hline Tracheal intubation & 9 & 90 & 1 & 10 & 0 & 0 & 7 & 87.5 & 1 & 12.5 & 0 & 0 \\
\hline Arterial Puncture & 10 & 100 & 0 & 0 & 0 & 0 & 8 & 100 & 0 & 0 & 0 & 0 \\
\hline Vein puncture & 10 & 100 & 0 & 0 & 0 & 0 & 8 & 100 & 0 & 0 & 0 & 0 \\
\hline Heel puncture & 9 & 90 & 0 & 0 & 1 & 10 & 8 & 100 & 0 & 0 & 0 & 0 \\
\hline PICC & 9 & 90 & 1 & 10 & 0 & 0 & 8 & 100 & 0 & 0 & 0 & 0 \\
\hline Tracheal suctioning & 3 & 30 & 7 & 70 & 0 & 0 & 4 & 50 & 4 & 50 & 0 & 0 \\
\hline Oral suctioning & 2 & 20 & 8 & 80 & 0 & 0 & 1 & 12.5 & 6 & 75 & 1 & 12.5 \\
\hline Umbilical catheter & 8 & 80 & 2 & 20 & 0 & 0 & 5 & 62.5 & 3 & 37.5 & 0 & 0 \\
\hline Gastric probing & 3 & 30 & 7 & 70 & 0 & 0 & 3 & 37.5 & 5 & 62.5 & 0 & 0 \\
\hline Extubation & 0 & 0 & 10 & 100 & 0 & 0 & 2 & 25 & 5 & 62.5 & 1 & 12.5 \\
\hline Removal of intravenous catheter & 3 & 30 & 5 & 50 & 2 & 20 & 3 & 37.5 & 5 & 62.5 & 0 & 0 \\
\hline Removal of adhesive & 10 & 100 & 0 & 0 & 0 & 0 & 8 & 100 & 0 & 0 & 0 & 0 \\
\hline Bath & 0 & 0 & 3 & 30 & 7 & 70 & 0 & 0 & 3 & 37.5 & 5 & 62.5 \\
\hline Anthropometric measurements & 0 & 0 & 8 & 80 & 2 & 20 & 0 & 0 & 3 & 37.5 & 5 & 62.5 \\
\hline Change of decubitus & 0 & 0 & 2 & 20 & 8 & 80 & 0 & 0 & 4 & 50 & 4 & 50 \\
\hline
\end{tabular}

Note: $P$ = painful; $S$ = stressful; $U$ = unpainful; $P I C C=$ peripherally inserted central catheter.

Table 3 - Distribution of the procedures with analgesia as preparation according to the respondent professional category, Campo Largo, Paraná, Brazil, 2017

\begin{tabular}{|c|c|c|c|c|c|c|c|c|c|c|c|}
\hline \multirow{2}{*}{ Procedure } & \multicolumn{2}{|c|}{ NU. $(n=10)$} & \multicolumn{2}{|c|}{ PT. $(n=10)$} & \multicolumn{2}{|c|}{ PHYS. $(n=8)$} & \multicolumn{2}{|c|}{ NSG. TECHN. $(n=37)$} & \multicolumn{2}{|c|}{ Total $(\mathrm{N}=65)$} & \multirow{2}{*}{$p$ value } \\
\hline & $\mathbf{n}$ & $\%$ & $\mathbf{n}$ & $\%$ & $\mathbf{n}$ & $\%$ & $\mathbf{n}$ & $\%$ & $\mathbf{n}$ & $\%$ & \\
\hline Selective tracheal intubation & 7 & 70 & 5 & 50 & 5 & 62.5 & 11 & 29.7 & 28 & 43.1 & 0.070 \\
\hline Endotracheal tube and airway suctioning & 6 & 60 & 7 & 70 & 2 & 25 & 6 & 16.2 & 21 & 32.3 & $0.002^{*}$ \\
\hline Gastric and enteral probing & 6 & 60 & 3 & 30 & 1 & 12.5 & 5 & 13.5 & 15 & 23.1 & $0.016^{*}$ \\
\hline Umbilical catheter insertion & 5 & 50 & 5 & 50 & 6 & 75 & 18 & 48.6 & 34 & 52.3 & 0.595 \\
\hline Insertion of PICC & 8 & 80 & 10 & 100 & 8 & 100 & 25 & 67.6 & 51 & 78.5 & 0.056 \\
\hline Phlebotomy & 8 & 80 & 8 & 80 & 7 & 87.5 & 17 & 45.9 & 40 & 61.5 & $0.030^{*}$ \\
\hline Arterial Puncture & 6 & 60 & 3 & 30 & 4 & 50 & 14 & 37.8 & 27 & 41.5 & 0.494 \\
\hline Vein puncture & 7 & 70 & 6 & 60 & 3 & 37.5 & 17 & 45.9 & 33 & 50.8 & 0.435 \\
\hline Heel puncture & 4 & 40 & 2 & 20 & 2 & 25 & 8 & 21.6 & 16 & 24.6 & 0.666 \\
\hline Intramuscular or subcutaneous injection & 3 & 30 & 2 & 20 & 2 & 25 & 5 & 13.5 & 12 & 18.5 & 0.631 \\
\hline Lumbar puncture & 4 & 40 & 5 & 50 & 3 & 37.5 & 3 & 8.1 & 15 & 23.1 & $0.010^{*}$ \\
\hline Chest drainage & 8 & 80 & 8 & 80 & 8 & 100 & 17 & 45.9 & 41 & 63.1 & $0.008^{*}$ \\
\hline Fundoscopy & 3 & 30 & 3 & 30 & 1 & 12.5 & 7 & 18.9 & 14 & 21.5 & 0.709 \\
\hline Postoperative care & 9 & 90 & 10 & 100 & 7 & 87.5 & 21 & 56.7 & 47 & 72.3 & $0.013^{*}$ \\
\hline Others - Installation of CPAP & 0 & 0 & 0 & 0 & 0 & 0 & 1 & 2.7 & 1 & 1.5 & - \\
\hline
\end{tabular}

Note: $N U=$ nurses; $P T=$ physical therapists; $P H Y S=$ physicians; NSG. TECHN = nursing technicians; $P I C C=$ peripherally inserted central catheter, $C P A P=C$ Continuous Positive Airway Pressure; ${ }^{*}$ significant difference $(p<0.05)$.

The same thing occurred in gastric or enteral probing, in which analgesia for performing the procedure was mentioned with greater frequency among nurses and physical therapists $(60 \%$ and $30 \%$, respectively) when compared with the physicians and nursing technicians ( $12.5 \%$ and $13.5 \%$, respectively).

For the procedures phlebotomy, lumbar puncture, chest drainage, and postoperative care, the frequencies of procedures with analgesia were significantly different in the category of nursing technicians when compared with the other professional categories.

In relation to the types of analgesia described in Table 4, fentanyl was the most cited drug (33.8\%) for pharmacological analgesia for all professional categories, and paracetamol was the least cited $(1.5 \%)$ by the participants of the study.
The frequency of use of fentanyl as analgesic for performance of the painful procedures proved to be significantly different between the professional categories; nurses and physicians with frequencies greater ( $70 \%$ and $62.5 \%$, respectively) than those of physical therapists and nursing technicians $(10 \%$ and $24.3 \%$, respectively).

Among the nonpharmacological measures for the management of pain and stress of the NB, restraint (26.2\%) and nonnutritive suction (23.1\%) were the most cited. A statistical significance between the professional categories is observed; the frequency of the use of restraint was greater in the categories of nurses and physical therapists (60\% and 30\%, respectively) compared with that of physicians and nursing technicians ( $25 \%$ and $16.2 \%$, respectively). 
Table 4 - Distribution of measures for pharmacological and nonpharmacological analgesias according to the respondent category of health professional, Campo Largo, Paraná, Brazil, 2017

\begin{tabular}{|c|c|c|c|c|c|c|c|c|c|c|c|}
\hline \multirow{2}{*}{ Tipo de analgesia } & \multicolumn{2}{|c|}{ TECHN. $(n=10)$} & \multicolumn{2}{|c|}{ PT. $(n=10)$} & \multicolumn{2}{|c|}{ PHYS. $(n=8)$} & \multicolumn{2}{|c|}{ NSG. TECHN. $(n=37)$} & \multicolumn{2}{|c|}{ TOTAL (N = 65) } & \multirow{2}{*}{$p$ value } \\
\hline & $\mathbf{n}$ & $\%$ & $\mathbf{n}$ & $\%$ & $\mathbf{n}$ & $\%$ & $\mathbf{n}$ & $\%$ & $\mathbf{n}$ & $\%$ & \\
\hline \multicolumn{12}{|l|}{ Pharmaceutical Agent } \\
\hline Midazolam & 2 & 20 & 1 & 10 & 3 & 37.5 & 1 & 2.7 & 6 & 9.2 & 0.025 \\
\hline Fentanyl & 7 & 70 & 1 & 10 & 5 & 62.5 & 9 & 24.3 & 22 & 33.8 & $0.005^{*}$ \\
\hline Dipyrone & 1 & 10 & 3 & 30 & 3 & 37.5 & 4 & 10.8 & 11 & 16.9 & 0.176 \\
\hline Paracetamol & 0 & - & 0 & 0 & 1 & 12.5 & 0 & 0 & 1 & 1.5 & - \\
\hline $25 \%$ Glucose & 5 & 50 & 2 & 20 & 2 & 25 & 9 & 24.3 & 18 & 27.7 & 0.389 \\
\hline Lidocaine & 3 & 30 & 2 & 20 & 3 & 37.5 & 6 & 16.2 & 14 & 21.5 & 0.520 \\
\hline Anesthetic eye drop & 1 & 10 & 0 & 0 & 0 & 0 & 0 & 0 & 1 & 1.5 & - \\
\hline \multicolumn{12}{|l|}{ Nonpharmacological } \\
\hline Restraint & 6 & 60 & 3 & 30 & 2 & 25 & 6 & 16.2 & 17 & 26.2 & $0.048^{*}$ \\
\hline Winding & 5 & 50 & 0 & 0 & 0 & 0 & 0 & 0 & 5 & 7.7 & - \\
\hline Nonnutritive suction & 6 & 60 & 2 & 20 & 2 & 25 & 5 & 13.5 & 15 & 23.1 & $0.022^{*}$ \\
\hline Positioning & 1 & 10 & 0 & 0 & 0 & 0 & 1 & 2.7 & 2 & 3.1 & - \\
\hline Red Reflex Test & 1 & 10 & 0 & 0 & 0 & 0 & 0 & 0 & 1 & 1.5 & - \\
\hline Maternal lap & 1 & 10 & 0 & 0 & 0 & 0 & 1 & 2.7 & 2 & 3.1 & - \\
\hline Skin-to-skin contact & 1 & 10 & 0 & 0 & 0 & 0 & 0 & 0 & 1 & 1.5 & - \\
\hline
\end{tabular}

Note: $N U=$ nurses; $P T=$ physical therapists; $P H Y S=$ physicians; $N S G . E N F=$ nursing technicians; ${ }^{*}$ significant difference $(p<0,05)$.

Regarding the use of nonnutritive suction, its frequency was greater in the category of nurses (60\%) and physicians (25\%) compared with that of physical therapists (20\%) and nursing technicians (13.5\%).

One highlights that the nurses were the professionals who mentioned measures for analgesia with greater frequency (both pharmacological as nonpharmacological) during painful procedures in the NICU studied.

\section{DISCUSSION}

This study shows important results about the identification of painful procedures by health professionals and the adoption of measures for treatment of neonatal pain and ascertains the existence of gaps of practices that lead to inadequate management of pain in the neonatal unit.

The identification of the population interviewed as being almost all female agrees with other studies, a fact that reflects the universal issue of genre of the health professional, especially in the nursing staff and in the $\mathrm{NICU}{ }^{(8-10)}$.

Regarding the qualification of professionals in the field of neonatal pain, one found that a small proportion of professionals participated in courses and events on the subject. This fact was also evidenced in the study by Akuma and Jordan ${ }^{(11)}$, in which 58 out of the 62 physicians mentioned they did not receive training on pain and analgesia in their qualification, and 112 out of 137 nurses did not receive training on the subject.

Learning about pain during medical training shapes the future practice. A cross-sectional study with 180 medical students, 42 Pediatrics residents and 20 Neonatology residents from a public university in São Paulo, showed that, for the proper management of pain in neonatal units, structuring the formal knowledge and the practical learning is necessary, a training based on the newborn's care and comfort ${ }^{(12)}$.

All the health professionals considered the removal of adhesives, vein puncture, arterial puncture, lumbar puncture, insertion of phlebotomy and chest drainage painful. When asked about the procedures for which they make any intervention for pain relief (pharmacological or nonpharmacological), phlebotomy and chest drainage were the most referred to by professionals as pharmacological measures. One can observe the use of drugs was restricted to more invasive procedures, which showed rates of analgesia higher than $70 \%$ for three professional categories (nurses, physical therapists, and physicians), being the administration of fentanyl the most cited by the health professionals for analgesia.

The category of nursing technicians showed the lowest frequency of use of measures for analgesia during painful procedures, which may be due to the absence of permanent education in the institution on neonatal pain management, because a fragmented and inadequate practice is observed when caring for the NB subjected to painful procedures.

Although most health professionals with higher education had or sought professional qualification through graduate courses, this training has not contributed to the qualification of these professionals in neonatal pain management.

The training of nurses in pain management is paramount to guide the performance of middle level professionals for the control and prevention of pain. For this purpose, including this subject in the curricula of undergraduate and graduate courses of health professionals is necessary, in addition to updating the permanent education to ensure a safe practice concerning the rights of the NB hospitalized.

The procedure of peripherally inserted central catheter (PICC) and postoperative procedures were the most cited by health professionals with the use of measures for analgesia. In a study conducted in four Brazilian NICUs, in 2001, 2006 and 2011, a significant increase in the use of analgesics in the postoperative period was observed: from $33 \%$ in 2001 to $89 \%$ in $2011^{(13)}$. However, this study also found that $10 \%$ of the NBs did not receive analgesia in the first three postoperative days.

National and international ${ }^{(14)}$ guidelines ${ }^{(15)}$ recommend that health professionals use analgesia in neonatal period in all potentially painful 
procedures, such as chest drainage, tracheal intubation, insertion of central catheter, multiple arterial, vein and heel punctures, and surgical procedure of any extent, among others. According to the guidelines, using opioid analgesics is important for treatment of pain in the critically sick newborn, and the most used are morphine, fentanyl, and tramadol. Pain can also be treated with nonsteroidal anti-inflammatory drugs when it is mild or moderate or when it is associated with an inflammatory process, particularly in situations in which the opioid-induced respiratory depression should be avoided. This group of drugs includes paracetamol, acetylsalicylic acid, diclofenac, ibuprofen, indomethacin, and dipyrone.

The pharmacological measures to relieve and treat neonatal pain most cited by health professionals were: fentanyl (33.8\%), $25 \%$ glucose $(27.7 \%)$, lidocaine $(21.5 \%)$, dypirone $(16.9 \%)$, midazolam (9.2\%), and paracetamol (1.5\%). One observes that in the NICU, pharmacological analgesia was referred to by a small percentage of health professionals during painful procedures, that is, it proved to be inadequate or insufficient. The administration of fentanyl was the most frequent in the professional categories of nurses and physicians, which can be justified by the prescription of opioids in invasive procedures with the insertion of PICC, performed by the nurses, and the administration of medicine is requirement in the protocol and in the postoperative period, through medical prescription.

Intravenous continuous infusion of fentanyl is used due to the stability of the therapeutic serum levels of the drug. However, it triggers the phenomenon of tolerance, with the need for increasing doses of medication to obtain the analgesic effect desired ${ }^{(16)}$.

The effectiveness and necessity of using pharmacological interventions for neonatal pain relief are recognized in scenarios of care for the premature, but these interventions have undesirable side effects ${ }^{(16)}$, thus requiring in-depth assessment of the indication of these drugs, considering the benefit-cost ratio for each patient.

Inadequate pharmacological analgesia is not exclusive to this scenario, another Brazilian study, conducted with nurses working in NICUs of hospitals in Curitiba and in the metropolitan region, also showed low use of pharmacological measures for pain relief during procedures in $\mathrm{NB}^{(9)}$.

Another Brazilian study(9), conducted in a public hospital of the state of São Paulo, with health professionals working in NICU and intermediate care unit, pointed fentanyl as the drug most used in NB for pain relief, followed by paracetamol.

A study conducted in the United Kingdom(11), aimed at assessing the knowledge and practice of nurses and physicians on the assessment and treatment of pain in NICU, showed the most cited drugs for analgesia in newborns were: morphine, fentanyl, codeine, paracetamol, sucrose, chloral hydrate, and ibuprofen.

The use of other drugs for analgesia was very low, especially of paracetamol, which is the only drug safe for newborns ${ }^{(16)}$ in the category of non-opioid analgesics used in mild to moderate pain, as well as of nonpharmacological interventions. Thus, a significant and worrying fact is that professionals consider most of the routine procedures in the NICU painful, but reported little intervention to prevent or relieve pain. Particularly for heel puncture and intramuscular injection, procedures considered painful, possibilities of nonpharmacological measures are pointed, such as: restraint, winding, sweetened solutions, and Kangaroo position ${ }^{(14,17)}$.
The use of $25 \%$ glucose was also very low $(27.7 \%)$ in this study. The effectiveness of the use of sweetened solution was shown in several studies ${ }^{(18-19)}$. Doses from 0.5 to $2 \mathrm{ml}$ of sucrose administered orally two minutes before the painful procedure, associated with nonnutritive suction, showed a reduction from 1-2 points in the scale of pain ${ }^{(18)}$. By contrast, an international study $^{(20)}$ stated that the administration of sucrose in neonate before acute painful procedures can decrease both physiological and behavioral manifestations of discomfort, but it does not recommend analgesia. The authors also report that questions related to sucrose remain unanswered, which does not define sucrose as an effective alternative to neonatal pain relief.

The international study ${ }^{(21)}$ aimed at determining whether the $24 \%$ sucrose solution administered orally, before insertion of a peripheral intravenous catheter, decreases the neonatal pain found no changes in pain responses between the groups of newborns. The study results did not confirm whether $24 \%$ sucrose administered before insertion of peripheral intravenous catheter interferes in the child's pain response. However, the authors pointed out that that was the first study to evaluate the effects of $24 \%$ sucrose in the insertion of peripheral intravenous catheter and that replication of the study is required before the generalization of the findings. The conclusion is that a gap exists in the knowledge of the repeated use of sucrose as gold standard measure for neonatal pain management ${ }^{(20)}$.

Another important datum verified in this study was the low use of analgesia in lumbar puncture (26.1\%). This reality was verified in another study ${ }^{(12)}$ and can derive from the fact that many professionals do not consider that the pain resulting from this procedure is intense enough to require analgesia.

A relevant datum evidenced in this study was that $100 \%$ of nurses considered the endotracheal tube suctioning painful, followed by physical therapists (70\%). Nonetheless, when asked about the use of analgesic measures during the procedure, the category of physical therapists showed the highest percentage in the use of analgesia (70\%), followed by nurses (60\%).

In this NICU studied, physical therapists care for NBs for 24 hours and are the responsible for performing the endotracheal tube suctioning, which justifies the increased use of analgesia. However, a Brazilian study ${ }^{(22)}$, aimed at investigating the academic and professional knowledge of pain, showed the professionals of physical therapy showed inconsistency between their theoretical knowledge and their roles in the handling of pain and humanized pain care. This is due to the inadequate education on the topic, which is an additional subtheme in the curriculum.

Oral suctioning was the procedure considered stressful for all professional categories; however, for this procedure, interventions for pain relief were mentioned by a minority of professionals. However, the winding or restraint proven to be effective as measures of analgesia to perform this procedure ${ }^{(19)}$.

One observed that the winding and the restraint help in reducing the physiological and behavioral stress caused by acute pain during painful and stressful procedures. These methods are even more effective when associated with other measures for pain relief. However, the winding alone is not effective in moderate to severe pain procedures ${ }^{(15)}$.

Most of the health professionals did not consider bath as a stressful procedure. The activity may provide comfort to the 
full-term NBs by reminding them of the liquid and warm environment of their mothers' womb ${ }^{(13)}$. However, for the preterm newborns, it consists of an excessive manipulation that can lead to unnecessary stress. An Italian study, conducted with eleven NBs with gestational age between 32 and 35 weeks, found bath and weighing caused stress for NBs until 35 weeks of gestational age, who need 5 minutes of warm and winding after the procedure for recovery of stability ${ }^{(23)}$.

The service, scenario of this study, has no protocol to manage the pain and stress in the NICU. Some strategies are used for pain relief, but without standardization or systematization of the actions. In a Brazilian study, the absence of protocols and guidelines that use validated scales and pharmacological and nonpharmacological measures for a systematized neonatal pain relief based on evidences for pain assessment was also observed ${ }^{(4)}$.

Another study conducted in 89 Japanese NICUs showed $60 \%$ of them had no protocols for pain relief in painful and therapeutic procedures $^{(24)}$.

A Brazilian study ${ }^{(10)}$ verified that, when asked about the existence of protocols, guidelines or routines for the assessment and treatment of pain in newborns, $33.3 \%$ of nurses working in NICU in Curitiba and in the metropolitan region answered that these instruments existed, $41.2 \%$ claimed that the latter did not exist, and $25.5 \%$ did not know the answer. The absence of institutional and training protocols suitable for neonatal pain management is the main barrier to the control of pain in NICUs ${ }^{(25)}$.

However, one of the stimuli for the improvement in the quality of the care provided to newborns is to implement evidence-based policies for the appropriate neonatal pain management ${ }^{(26)}$.
One confirmed that this hospital needs to develop a protocol for management of pain and stress in NB, aimed at the quality of the care provided to newborns.

\section{Study limitations}

As a limitation, the authors consider the absence of previous studies on the classification of the painful and stressful procedures by health professionals, especially by the categories of physical therapists and physicians.

\section{Contributions to the field of nursing, health, or public policy}

The estimation is that the findings of this study can contribute to future actions, based on evidences, to qualify the pain management in newborns in neonatal units through the implementation of protocols to assess and treat pain.

\section{CONCLUSION}

In this study, the professionals classified the routine procedures in the neonatal intensive care units as painful, stressful and unpainful and identified those they considered the most painful; however, insufficient analgesia measures were evidenced in the NICU studied. One believes that this finding may be explained by the staff's lack of knowledge of the existence of these measures, the deleterious consequences for the NB through the overexposure to painful and stressful procedures during the hospitalization, and by the lack of a protocol for management of pain and stress in the NICU.

\section{REFERENCES}

1. Cruz MD, Fernandes AM, Oliveira CR. Epidemiology of painful procedures performed in neonates: a systematic review of observational studies. Eur J Pain. 2016;20(4):489-98. doi: 10.1002/ejp.757

2. Kyololo OM, Stevens B, Gastaldo D, Gisore P. Procedural pain in neonatal units in Kenya. Arch Dis Child Fetal Neonatal Ed. 2014;99(6):F464-7. doi: 10.1136/archdischild-2014-306003

3. Carbajal R, Rousset A, Danan C, Coquery S, Nolent P, Ducrocq S, et al. Epidemiology and treatment of painful procedures in neonates in Intensive Care Units. JAMA. 2008;300(1):60-70. doi: 10.1001/jama.300.1.60

4. Christoffel MM, Castral TC, Daré MF, Montanholi LL, Gomes ALM, Scochi CGS. Attitudes of healthcare professionals regarding the assessment and treatment of neonatal pain. Esc Anna Nery 2017;21(1):e20170018. doi: 10.5935/1414-8145.20170018

5. Britto CD, Rao S, Nesargi S, Nair S, Rao S, Thilagavathy T, et al. PAIN - Perception and Assessment of Painful Procedures in the NICU. J Trop Pediatr. 2014;60(6):422-7. doi: 10.1093/tropej/fmu039

6. Sposito NPB, Rossato LM, Bueno M, Kimura AF, Costa T, Guedes DMB. Assessment and management of pain in newborns hospitalized in a Neonatal Intensive Care Unit: a cross-sectional study. Rev Latino-Am Enfermagem. 2017;25:e2931. doi: 10.1590/1518-8345.1665.2931

7. Zar JH. Biostatistical analysis. 5th ed. Upper Saddle River: Prentice Hall; 2009.

8. Amaral JB, Resende TA, Contim D, Barichello E. The nursing staff in the face of pain among preterm newborns. Esc Anna Nery 2014;18(2):241-6. doi: 10.5935/1414-8145.20140035

9. Capellini VK, Dare MF, Castral TC, Christoffel MM, Leite AM, Scochi CGS. Conhecimentos e atitudes de profissionais de saúde sobre avaliação e manejo da dor neonatal. Rev Eletr Enf. 2014;12(2):361-9. doi: 10.5216/ree.v16i2.23611

10. Costa T, Rossato LM, Bueno M, Secco IL, Sposito NPB, Harrison D, et al. Nurses' knowledge and practices regarding pain management in newborns. Rev Esc Enferm USP. 2017;51:e03210. doi: 10.1590/s1980-220x2016034403210

11. Akuma AO, Jordan S. Pain management in neonates: a survey of nurses and doctors. J Adv Nurs. 2012;68(6):1288-301. doi: 10.1111/j.1365-2648.2011.05837.x

12. Silva APM, Balda RCX, Guinsburg R. Identification of pain in neonates by medical students, residents in pediatrics and neonatology. Rev Dor. 


\section{2;13(1):35-44. doi: 10.1590/S1806-00132012000100007}

13. Prestes ACY, Balda RCX, Santos GMS, Rugolo LMSS, Bentlin MR, Magalhães M, et al. Painful procedures and analgesia in the NICU: what has changed in the medical perception and practice in a ten-year period? J Pediatr. 2016;92(1):88-95. doi: 10.1016/j.jped.2015.04.009

14. Ministério da Saúde (BR). Atenção à saúde do recém-nascido: guia para os profissionais de saúde [Internet]. Brasília: Ministério da Saúde; 2011 [cited 2018 Mar 10]. Available from: http://www.redeblh.fiocruz.br/media/arn_v1.pdf

15. Committee on Fetus and Newborn; Section on Anesthesiology and Pain Medicine. Prevention and management of procedural pain in the neonate: an update. Pediatrics [Internet]. 2016 [cited 2018 Mar 10]; 137(2):e20154271. Available from: http://pediatrics.aappublications.org/ content/pediatrics/137/2/e20154271.full.pdf

16. Hall RW, Anand JS. Pain management in newborns. Clin Perinatol. 2014;41(4):895-924. doi: 10.1016/j.clp.2014.08.010

17. Johnston C, Campbell-Yeo M, Disher T, Benoit B, Fernandes A, Streiner D, et al. Skin-to-skin care for procedural pain in neonates. Cochrane Database Syst Rev. 2017;2:CD008435. doi: 10.1002/14651858.CD008435.pub3

18. Stevens B, Yamada J, Ohlsson A, Haliburton S, Shorkey A. Sucrose for analgesia in newborn infants undergoing painful procedures. Cochrane Database Syst Rev. 2016;2016(7):CD001069. doi: 10.1002/14651858.CD001069.pub5

19. Carbajal R, Gréteau S, Arnaud C, Guedj R. Pain in neonatology. Non-pharmacological treatment. Arch Pediatr. 2015;22(2):217-21. doi: 10.1016/j.arcped.2014.07.001

20. Wilkinson DJC, Savulescu J, Slater R. Sugaring the pill: ethics and uncertainties in the use of sucrose for newborn infants. Arch Pediatr Adolesc Med. 2012 Jul 1;166(7):629-33. doi: 10.1001/archpediatrics.2012.352

21. Cook LM, Nichols-Dada J, Damani S, Lawrence V, Layson S, Mitchell D, et al. Randomized clinical trial of $24 \%$ oral sucrose to decrease pain associated with peripheral intravenous catheter insertion in preterm and term newborns. Adv Neonatal Care. 2017 Feb;17(1):E3-11. doi: 10.1097/ANC.0000000000000326

22. Santos ACN, Barbosa ML, Souza AG, Petto J. Knowledge of physical therapy students and professionals about pain: a systematic review. ABCS Health Sci. 2017;42(2):99-104. doi: 10.7322/abcshs.v42i2.1010

23. Bembich S, Fiani G, Strajn T, Sanesi C, Demarini S, Sanson G. Longitudinal responses to weighing and bathing procedures in preterm infants. J Perinat Neonatal Nurs. 2017;31(1):67-74. doi: 10.1097/JPN.0000000000000228

24. Ozawa M, Yokoo K. Pain management of neonatal intensive care units in Japan. Acta Paediatr. 2013;102(4):366-72. doi: 10.1111/apa.12160

25. Schultz M, Loughran-Fowlds A, Spence K. Neonatal pain: a comparison of the beliefs and practices of Jr physicians and current best evidence. J Paediatr Child Health. 2010;46(1-2):23-8. doi: 10.1111/j.1440-1754.2009.01612.x

26. Stevens B, Riahi S, Cardoso R, Ballantyne RCM, Yamada J, Beyene J, et al. The influence of context on pain practices in the NICU: perceptions of health care professionals. Qual Health Res. 2011;21(6):757-70. doi: 10.1177/1049732311400628 